\title{
Assessment of psychosocial aspects of divorcees employed in some institutes and colleges of the foundation of technical education in Baghdad city
}

\author{
${ }^{1 *}$ Abdullah E. Mecheser, ${ }^{2 *}$ Abdulkhaleq A. Al - Naqeeb ${ }^{3 *}$ Asmaa A. Obaid \\ ${ }^{1 *}$ Medical Health Technical College-Baghdad Iraq \\ 2 * Medical Health Technical College-Baghdad Iraq
}

\begin{abstract}
Descriptive analytic study to asses' psychosocial aspects of divorcees employers in some of institutes and colleges of the foundation of technical education. From September 2011-December 2012 to determine and to assess the psychology and social aspects and whichever aremore effective on the divorce states for employers in the foundation's institutes and colleges .The study sampling was convenient consist of (thirty) divorces consisted of (ten) who did not respond to questions because the period of their divorce was close and reserved on the response, because they think back to the case of the former matrimonial. Twenty who are the rest divorces consisted of (four) male and (sixteen) female who work in different functional professions .The researchers concluded that most of the divorced were affected by psychological and social factors. The assessment of the Psychological and social domains were reported as bad assessment with (100\%). Descriptive and inferential statistical methods (Frequency, Percentage, Mean of Score, Standard deviation, and Relative Sufficiency and chi square) were used. The researchers recommended establishing the guidance of education and psychology to follow up all divorces and to present management for any problems which cause the separation or divorce.
\end{abstract}

KEY WORDS: Divorce, Concept of divorce, Causes of divorce's, Divorce's individuals, Divorce's response.

\section{INTRODUCTION}

The concept of divorces is one that has become increasingly pertinent to today's society. People are bombarded by statistics about its rise and facts about the decreasing stability of the nuclear family. Rates of divorce have increased so greatly over the past few decades that people have come to fear the institution of marriage .About one -half of newlywed couples today are likely to end in separation(1).Divorce has become a looming shadow that seems to be spreading farther and farther across the United States (2). During the 1980s and 1990s thenumber of divorces raised, during the year 1993 decreased by $17.64 \%$ in comparison to the year 1983 .In the meantime the popularity of marriages ( officeof Population Censuses and Survey ) (4).Divorce was not always this escape from a marriage; however, over time repeated divorce has become common in some urban areas. A man may remarry right away, but a woman cannot for three months ( according to Islamic Rites ), tradition ally ,because she has to make sure that she's not pregnant. Divorced women usually return to their father or brother's homes where she receives the second half of her wedding dowry . Children of divorced parents belong to the father ,but mothers usually raise them until they are eight or nine before giving them to the fathers(5). The number of divorces in Iraq has risen steadily since 2004.but marriages far outstrips divorces, while the opposite was from 1995-2003 .Number of divorces have increased from 28. 690 in 2004 to 59.515 in 2011 .The wife may also request judicial separation before consummation in return for any dower and proven expenditure on the husband for the purposes of the marriage (14). All judicial divorces are considered lesser irrevocable .The wife may also obtain a khul ( to cut any relation with her divorcee ) from her husband in return for the consideration that are may lose her dowry. The option of puberty is not specifically regulated, but is mentioned in the provision defining the waiting period .The former husband is obliged to maintain the divorced wife (even if she was deemed nashiza)during her 'idda period .According to a legislation passed in 1983(14), the repudiated wife also has a right to live in the marital home without her former husband for three years provided that she was not disobedient , did not request or agree to the divorce, and does not own her own house or flat .The divorcee is entitled to custody of boys or girls until the age of 10,extendable to 15 years if it appears to be in the minor's best interests. Upon attaining 15 years , the ward choose which parent to live with, or choose any other relative if such choice appears reasonable to the court (14). Separation, which for benefits purposes is a far more important situation than divorce, can happen with little or no warning, throwing one or both parties into unexpected financial waters 4 .Causes of divorce never come alone in anyone's life. Divorces always bring trauma, financial and emotional distress, psychological upheaval and social loneliness. 
Divorces can be one of the most traumatizing events that happen in a person's life. It is an interesting topic especially from a sociological standpoint because it has no clean cause. It transcends race, gender, or level of education (2). Divorce is one of the most stressful events that families confront. Children begin to feel sad, anxious, abandoned and angry during a divorce. Divorce has been known to weaken parenting skills, especially during custody and child-support proceedings (3). The custody schedule might lead a child to feel that the parent who has less time with him chose the arrangement because they don't care. A drop in income going from two parents to one parent causes many problems. Children might have to give up extracurricular activities or more costly clothing. If child support is ordered, resentment towards the recipient could cause argument (3).

\section{Methodology Validity and Reliability of the Questionnaire:}

\section{Validity of the instrument:}

The content validity of the instrument was established through a panel of experts who had more than (25) years experience in their job. They were faculty member from the health and medical technology college in Baghdad ; institute of medical technology in Baghdad ; societal Department in Bagdad University and psychology Department in Bagdad University. They were asked to review questionnaire whether they agree or disagree with its items. The results of the review by experts revealed that all of them agreed that the items of the questionnaire were clear and adequate for the measurement in the study. They recommended minor changes that were performed on few items.

\section{Pilot study:}

It was carried out in the first of October 2011 on 20 divorcees, males and females working at the institute of medical technology and at the college of medical and Health technology in Baghdad. The author and expert used the instrument for each divorcee in the same time and place. Full data were collected by the researchers from those individuals twice with the interval of three weeks in order to test the reliability of patients. The result shows that reliability coefficient was $(0.93)$ for inter-examiners and $(0.94)$ for intra-examiner which was statistically acceptable.

\section{Reliability of the questionnaire:}

Determination of the reliability of the questionnaire was based on Alpha-Cronbach, correlation between forms, using its correction through Spearman Brown formula correction, and finally applying Guttmann Split-half criteria which were the ideal formulas to overcome, the difficulties of long scale items, to adjust the correlation Coefficient, and to give an estimation of the reliability for the entire test as shown in the table 1.

Table (1): Reliability Coefficients of the Studied Questionnaire's

\begin{tabular}{|l|l|l|l|}
\hline $\begin{array}{l}\text { Questionn } \\
\text { aire }\end{array}$ & $\begin{array}{l}\text { Standard } \\
\text { lower } \\
\text { bound }\end{array}$ & $\begin{array}{l}\text { Compa } \\
\text { values } \\
\text { red }\end{array}$ \\
\hline $\begin{array}{l}\text { Alpha( } \\
\text { Cronbach }\end{array}$ & 0.60 & 0.9607 & \\
\hline $\begin{array}{l}\text { Correlatio } \\
\text { netween } \\
\text { forms }\end{array}$ & 0.56 & 0.7123 & O.K. \\
\hline $\begin{array}{l}\text { Spearman } \\
\text { Brown }\end{array}$ & & & O.K. \\
\hline $\begin{array}{l}\text { Guttmann } \\
\text { Split- } \\
\text { half }\end{array}$ & 0.67 & 0.8320 & \\
\hline
\end{tabular}


1. A questionnaire consists of knowledge concerning information about patients with cervical pain, and psychological problems such as anxiety, stress, and depression. Twenty divorcees were included in this research. Age between (20-59) years. In this research Likert measurement scale had been used through the ordinal categories scale of (No, Sometime, and Yes) with scoring values $(1,2,3)$ respectively. Statistical methods: Data were analyzed through the application of descriptive and inferential of the statistical methods: Frequency, percentage, mean of score, standard deviation, and relative sufficiency with assessment according to the (upper/or under) cut off point $=66.66 \%$. In addition to that inferential statistics were used, to accept or reject the statistical hypotheses, they include: Frequencies, percentages, and cumulative percents, Contingency Coefficients (C.C), mean of score and standard deviation, relative sufficiency (RS\%), chi-square test for one criterion, binomial test for two categories dichotomous random variable. All calculations of the statistical methods which were used through applying (SPSS) ver. (10.0).

\section{Results and Findings:}

This section presents the findings of the data analysis systematically in table 2 and these correspond with the objectives of the study as follows:-

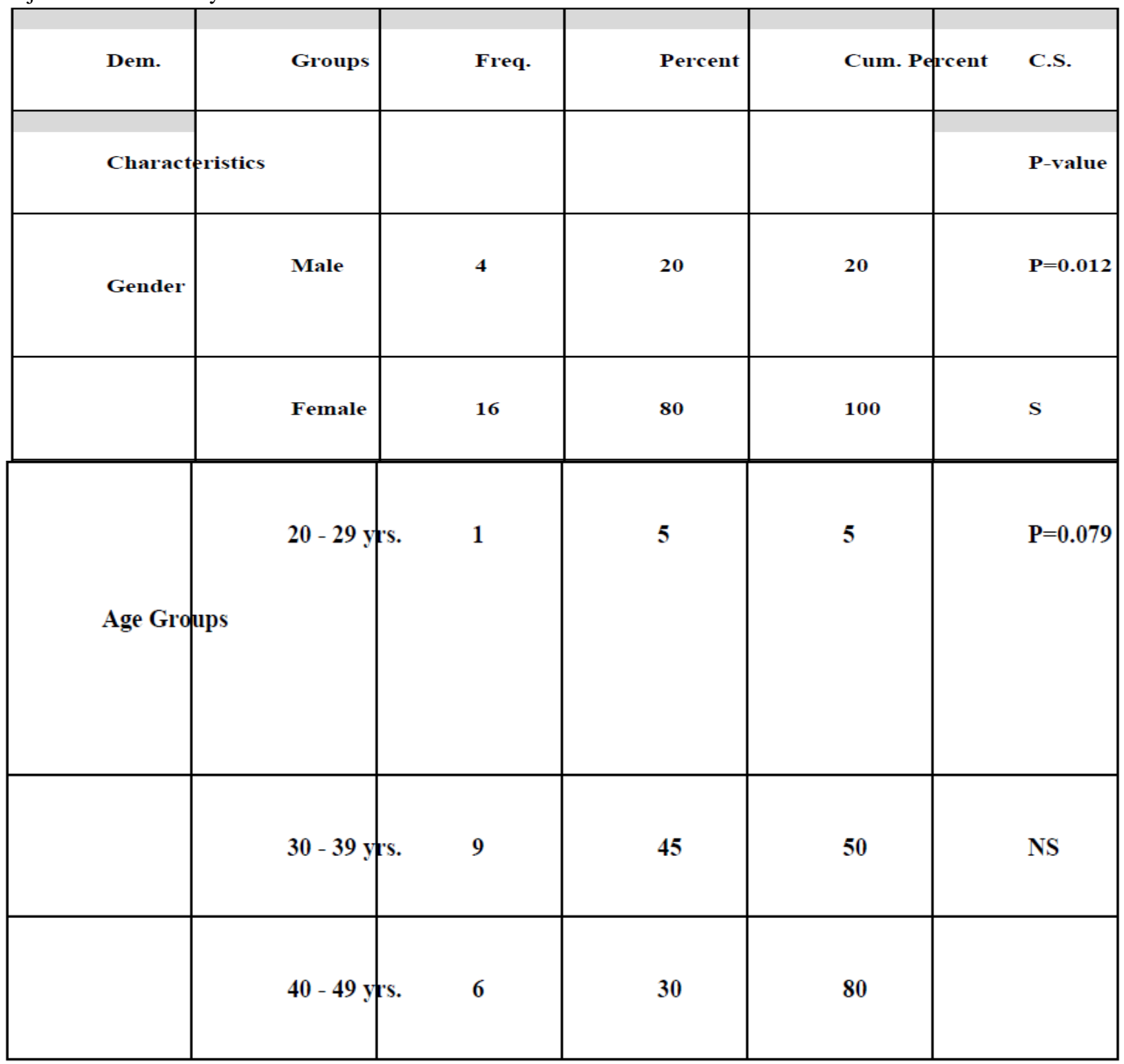


Assessment of psychosocial aspects of divorcees...

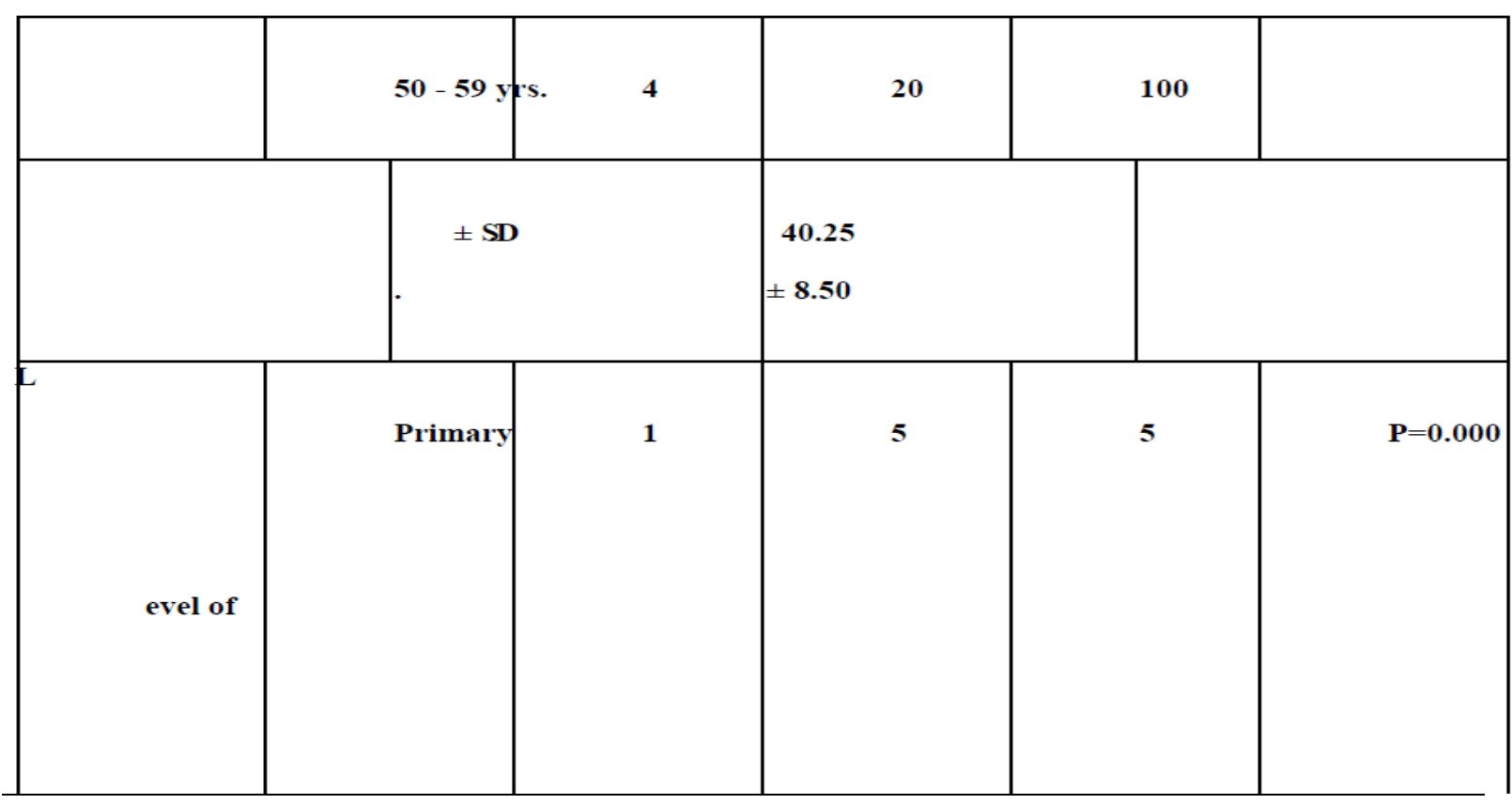

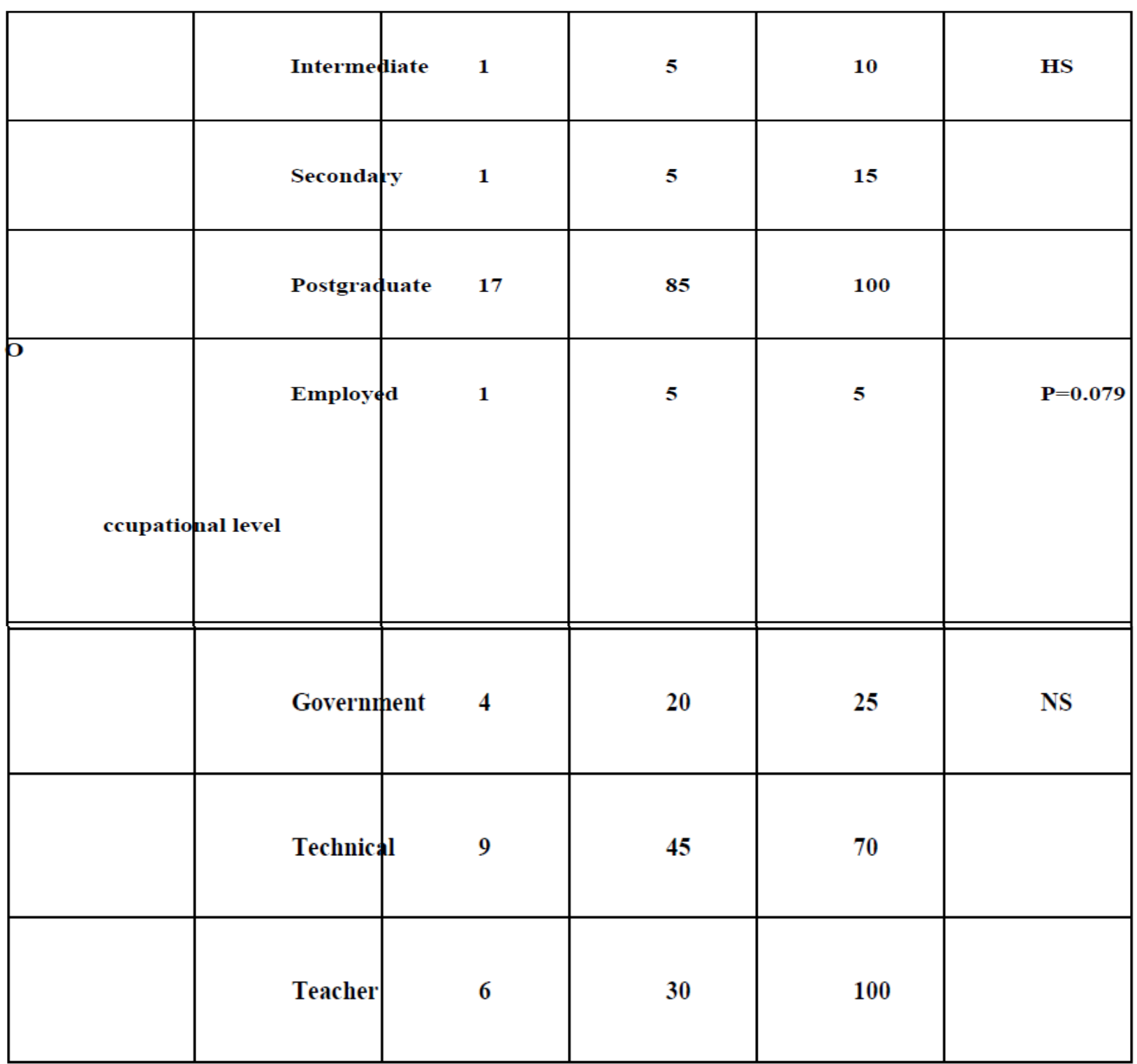


Assessment of psychosocial aspects of divorcees...

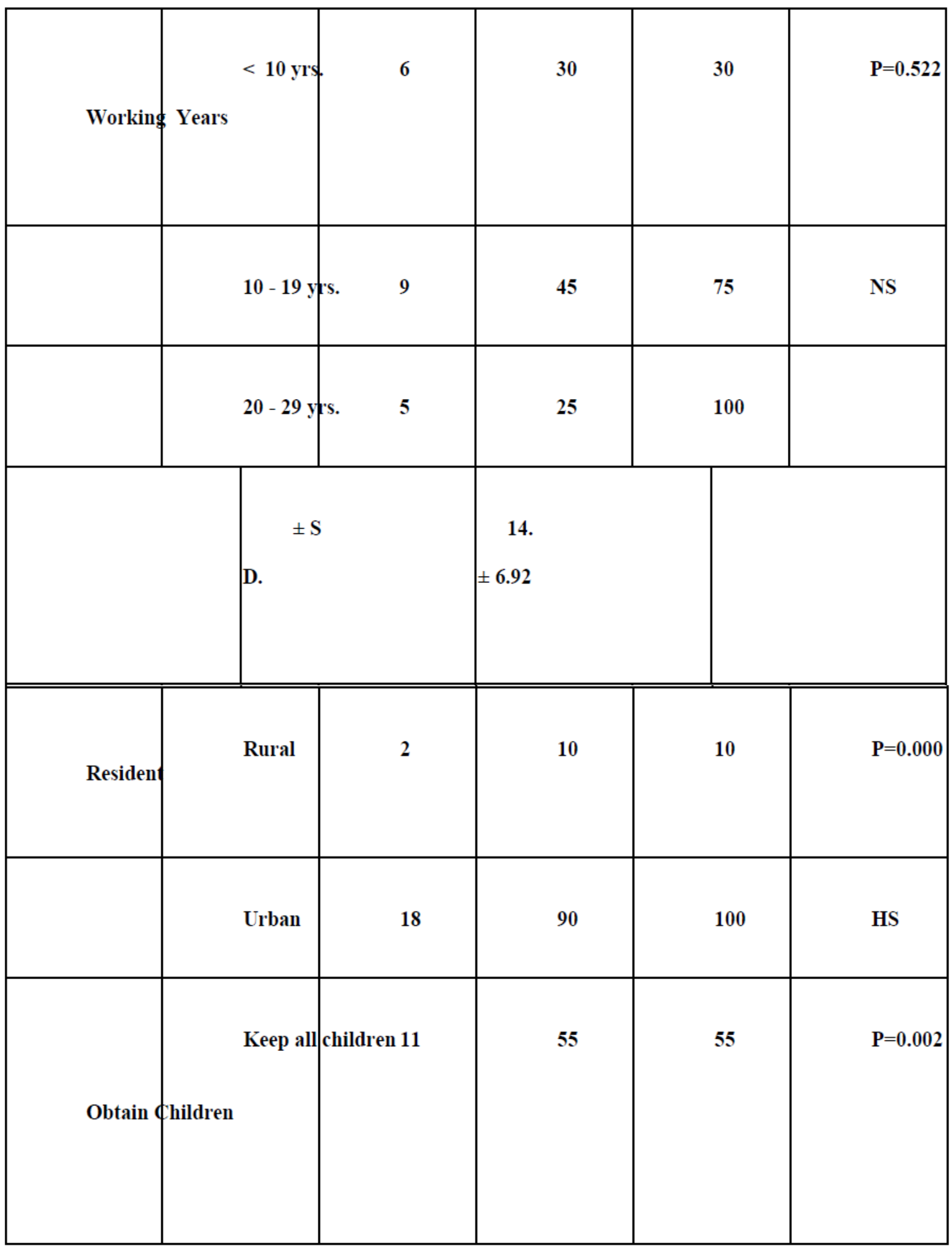




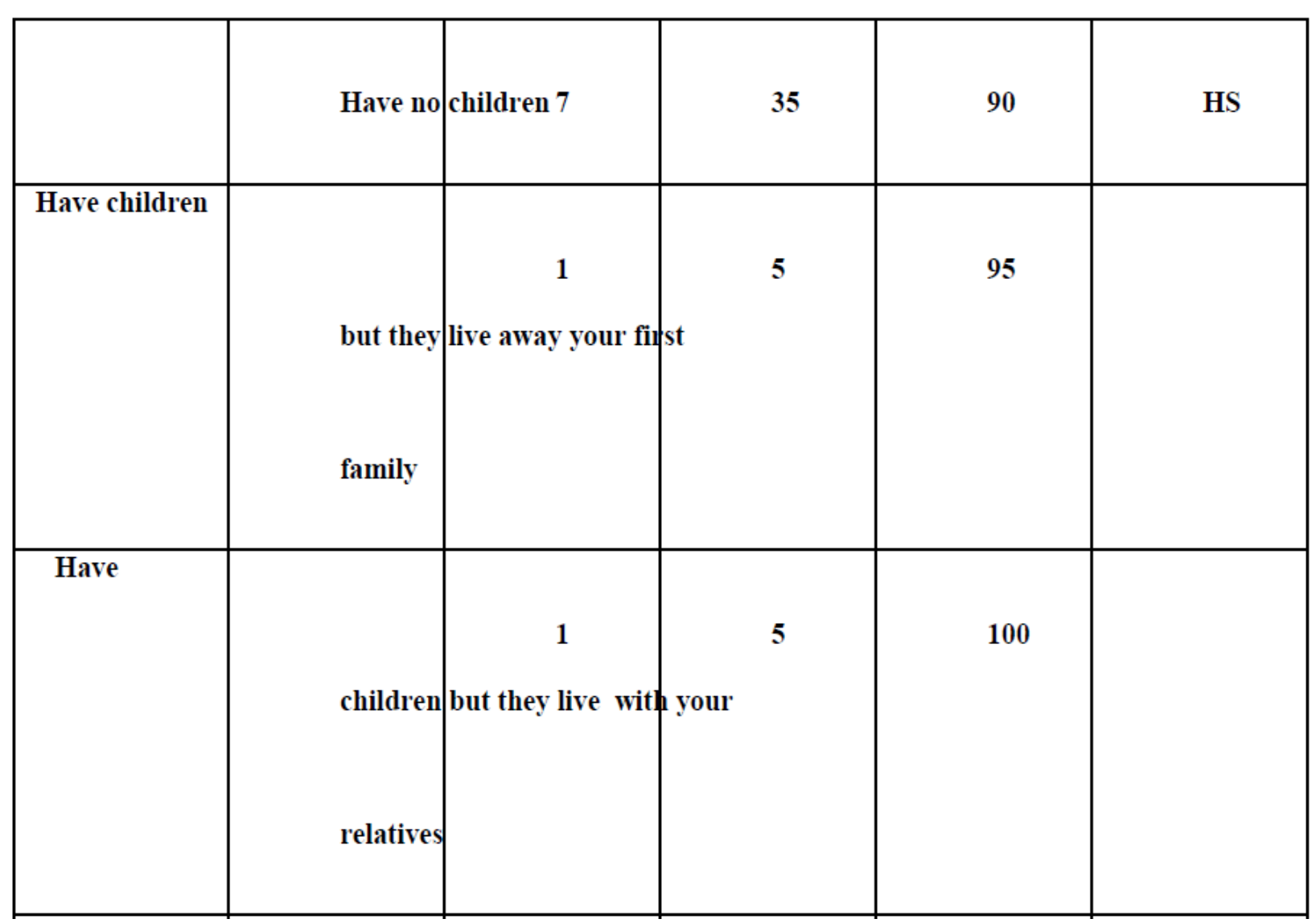

Table (2): Distribution of the Studied Groups According to Demographic haracteristics Variables.

\section{Continue...}

\begin{tabular}{|l|r|r|r|r|r|}
\hline Dem. & Groups & Freq. & Percent & Cum. Percent & C.S. \\
\hline Characteristics & & & & & P-value \\
\hline
\end{tabular}

Residential status Live alone 


\begin{tabular}{|r|r|r|r|r|r|}
\hline & Rent & 3 & 15 & 85 & HS \\
\hline \multirow{2}{*}{ long to fovernment } & 2 & 10 & 95 & \\
\hline & Other & 1 & 5 & 100 & \\
& & & & & \\
\hline
\end{tabular}

Freq: Frequency , Cum : Cumulative , P-value : Probability value ( Level of significant ), HS : Highly Significant, NS : Non

-Significant , S: Significant , :X -bar (mean value ), SD: Standard Deviation ,Yrs : Years, Dem : Demographical , C.S :

\section{Comparison Significant}

Table (2) showed that the majority sample of the study were females, registered (80\%) in the major age group (30-39) that registered (85\%) postgraduate in the education level, $(45 \%)$ was technical in the working years $(10$ 19 years), their house was Urban (90\%) of the residence, they had children living with them $(55 \%)$. The monthly income was sufficient (40\%), the residential status composed (30\%) when they live alone or when they , regarding gender there was significant difference in gender among the employee and so on

Table (3): Distribution of Psychosocial Problems of Divorcee individuals

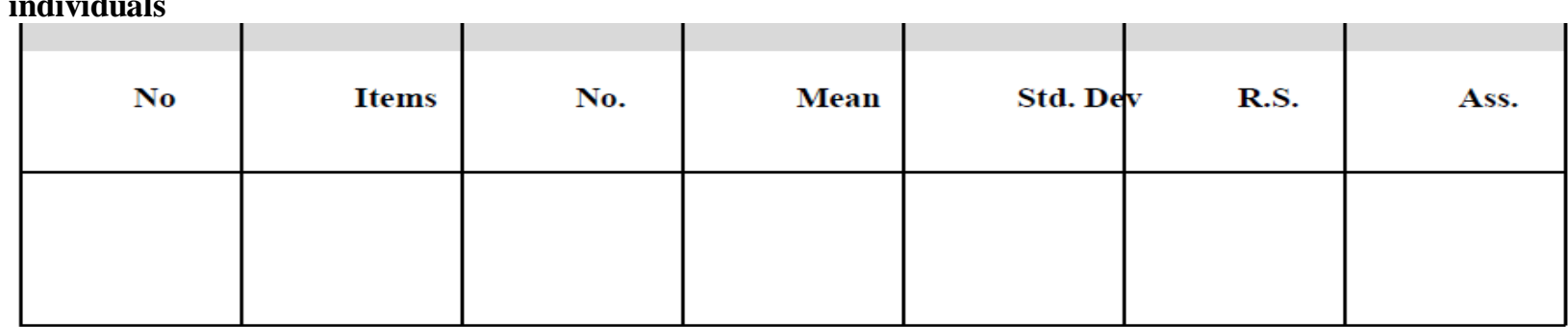


Assessment of psychosocial aspects of divorcees...

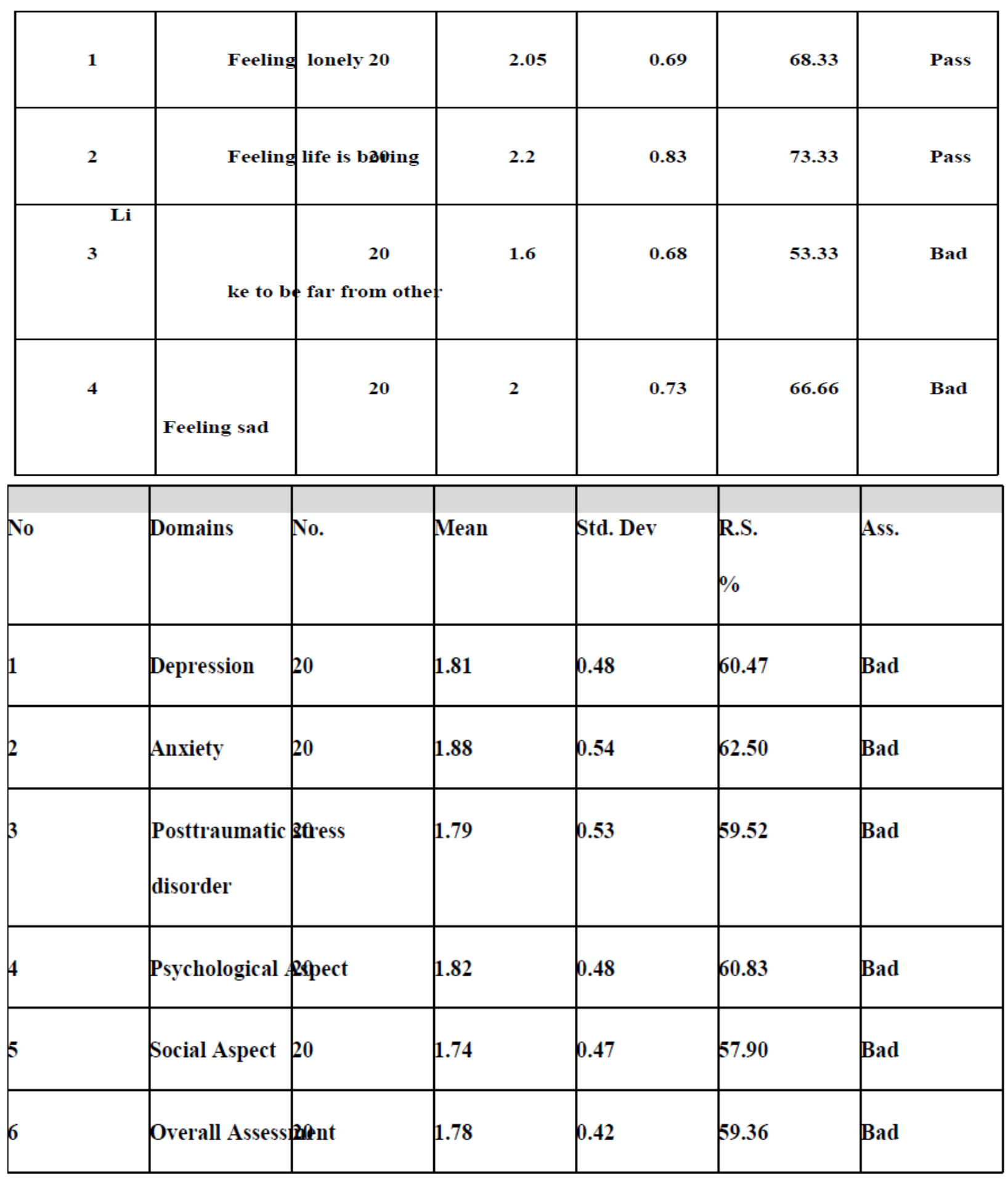

Once again predicting or studying the distribution's behavior of some related variables (demographical characteristics) for the studied divorces' correlation through the contingency coefficients of the contingency tables had been constructed in table 5 . Which illustrates of accepted the statistical hypotheses of non restricted distribution among different levels of the predicted variables and the two categories of an overall Response of assessment which were reported (Under- Upper Cutoff point=2).

DISCUSSION:-

Table 2 demonstrates that female constitutes $80 \%$ of cases of the divorcees, and this in accordance with National Center for Health Statistics reports. Adjustment among divorced individuals is positive with education (12), employment (13) and large networks of supportive kin and friends (14). Unhappiness, distress, depression and health problems largely subside two or three years after separation and new relationships tend to predict 
adjustment to divorce (1). Because of the financial and social problems faced after divorce, most people assume that generally husbands have instigated divorce since the introduction of no-fault divorce . Yet women file for divorce and are often the instigators of separation, despite a deep attachment to their children and the evidence that many divorces harm children. Furthermore, divorced women in large numbers reveal that they are happier than they were while married (9).Divorce rate in Iraq increased because of economic and social reasons, Leaving $(73 \%)$ of the women and $(58 \%)$ of men dropping from their healthy standard living, children are the most distressed personalities during the divorce procedures. They suffer stability and attitude issues after their parents get separated or divided. Their attention is diverted from the relationships to all the years to come ahead of their lives (6). The emotional stress of being away from the biological parents will remain on their minds that can hardly be healed or cured. They will face difficulties in communicating and sharing their thoughts fearing they wouldn't be able to trust anybody again (6). They will face a lack of interaction and interest. Teenagers who go through such procedure get involved in drugs, alcohol and other harmful activities (6). Drastic effects of divorce on the families begin with financial crisis. Following the regulations for a divorce, various families invest a huge toll of money and they are most likely to start a new independent life afterwards. The court divides the marital property equally and justifiably but the personal property that is not related to the marriage remains unaffected and undivided (6). Seventy percent of our studied divorcees live in private, while $30 \%$ lives alone . Women initiate divorce twice as often as men, $(90 \%)$ of divorced mothers have custody of their children (even if they did not receive it in court ), $(60 \%)$ of people under poverty guidelines are divorced women and children. Single mothers support up to four children on an average aftertax annual income of (12.200\$). (65\%) divorced mothers receive no child support (figure based on all children who could be eligible, including never-married parents, when fathers have custody, and in parents without court orders); (75\%) receive court-ordered child support ( and rising since inception of uniform child support guidelines, mandatory garnishment and license renewal suspension). After divorce women experience less stress and better adjustment in general than do men (3). Data in table 3 and 4 involve psychosocial factors effect on divorces individuals, there was moderate acuity in overall assessment. The stress of separation and divorce places both men and women at risk for psychological and physical health problems such as alcoholism, drug abuse, depression, psychosomatic problems, and accidents (15). Divorce also affects the couple's relationship as parents and the way in which they fulfill their parental functions(16), and a period of less effective parenting is often found following divorce, for both emotional and practical reasons(1), (17); (15); (18). For example, changes in living arrangements and household economics can directly affect parenting functions. Both residential mothers and fathers tend to feel overburdened by their parenting and life responsibilities following separation and divorce (16). Increases in divorce rates and reduction of marriage rates are due to changing attitudes about the functionality of marriage. As divorce becomes more and more commonplace, people lose their sense of trust in the formation of marriage. Large drops in the rates of marriage are a result of the changing attitudes that are sweeping youth of the United States. In response to the decreasing faith in marriage, many people have chosen to cohabitate prior to marriage and often times not join marriage at all(2). This is especially true when one or both of the people involved do not come from a nuclear family. Continuingly dropping marriage rates are starting trends of cohabitation that may continue to spread. Changes in the family structure such as this are greatly changing the way children are raised. It is no longer uncommon for a child to be raised in either a single-parent household or one with a parent and a stepparent (2). In fact these types of families have become very widespread. Growing up in households run by different authoritative systems can cause trauma in a child. However children are not the only ones susceptible to emotional strain(2). Men are usually confronted with greater emotional adjustment problems than women. The reasons for this are related to the loss of intimacy, the loss of social connection, reduced finances and the common interruption of the parental role. Men re-marry more quickly than women. Many researchers of divorce, link separation to different levels of stress(1). Children rated atmosphere at home and the atmosphere at the non-resident parent's home, how well they got along with their siblings, and how socially involved they were(1). Stress and overall frustration builds and the separation process will continue if the couple cannot repair the damage done to their relationship. If the progression to divorce does continue to the point where separation is unavoidably close at hand, the initiator of the divorce will most likely feel relieved when the process has finally ended. However, the spouse that opposed the divorce may not fully accept the reality of the annulment until it is finished and is legally complete. This spouse is much more likely to grieve over the divorce after it has concluded. Numerous studies showed that there are lasting psychological effects on adults from divorce. They have been shown to be unhappy and have lower levels of self concept(10). Aside from emotional damage, adult victims of divorce have been shown to potentially have more health complications than individuals involved in lasting marriages(1). Marital separation and divorce can be two of the most difficult events in an adult's life.

Much of the stress comes from the need to reorganize daily tasks and responsibilities, the loss of a significant relationship, and the need to establish a new identity as a single person(1). The following complaints are also common : behavioral changes (crying, withdrawal from others, aggression, substance misuse (drugs, alcohol, tobacco, food ), agitation, exhaustion, restlessness, Disturbed sleep, emotional changes, sadness, guilt, 
depression, anxiety, tensions, irritability, fear, fatigue, mood swings, thoughts and feelings (thinking that you cannot cope with). Feeling frightened for an unknown reason, feeling helpless, worrying about everything, large or small. Feeling afraid that something bad will happen, having nightmares, feeling that you are falling apart, having the same worrisome thought, having a negative view of the world, having a negative view of yourself, feeling bored with everything, being unable to concentrate, feeling worthless, feeling unable to make decisions). One of these is the Divorce-Street-Adjustment theory(1). Stress and overall frustration builds and the separation process will continue if the couple cannot repair the damage done to their relationship. If the progression to divorce dose continue to the point where separation is unavoidably close at hand, the initiator of the divorce will most likely feel relieved when the process has finally ended. However, the spouse that opposed the divorce may not fully accept the reality of the annulment until it is finished and is legally complete. This spouse is much more likely to grieve over the divorce after it has concluded(2).

The impact of separation or divorce on parents and their children is far-reaching and complex. It impacts on all aspects of family life and the process of adjustment is important for individuals, their families and our society. The Australian Psychological society (APS) takes this issue seriously and sees it as a significant public issue. Psychologists can contribute practice skills and knowledge of preventive approaches to separation, mediation of conflict, and social and practical supports for families in transition(11). Table 5 shows that the distribution of the studying items of divorcee individuals through the two dichotomous of Response had no relationship with their demographical characteristic variables and we can conclude that the problem can be amended for all individuals of the studied population in concern with their divorce status whatever the differences in their demographical characteristics variables would be not significant. Gender dose not play a role in calculating levels of post-marital emotional stress. With results from each end of the spectrum, these studies do not prove that one sex suffers more emotionally following a divorce. In either case, both partners are likely to suffer from lower levels of overall well-being (1).The results has reported that the distribution of the studying items of divorce's individuals through the two dichotomous of Response had no relationship with their demographical characteristics variables and we can conclude that the studied problem can be amended for all individuals of the studied population concerning with (divorces status) whatever the differences with their (demographical characteristics) variables would be.

\section{CONCLUSIONS:}

1-Individual's are psychologically and socially Burden by separation or divorce. The individuals' Response through overall assessment was bad in all domains such as anxiety, depression, posttraumatic stress disorder and psychosocial aspects.

2-The demographical characteristic variables in our research which cause the separation or divorce have effect on the family, while the associations among predicating characteristics had differences and no relationship between them. They were not significant.

\section{Recommendations}

Psychologists' and professionals working with separated families help parents: To establish the guidance of education and psychology to follow up all divorces and to present management for any problems which cause the separation or divorce that effects the family, through to present cultural conferences and programs to prevent or reduce separation or divorce conditions

\section{ACKNOWLEDGEMENT:}

I would like to express my deepest gratitude and appreciation to Dr . basim H.Bahir, Dr . Sulaf A.Hussain , Dr. Nawfal K . AL-Damlooji , Dr. Muna S. Dawood and Mr. Adnan G. ALwan for their scientific guidance, patience, and help during our study .

\section{References :}

[1]. Amato, Paul R: (The consequences of divorce for adults and children). Journal of Marriage and Family, 2000,62;12691288.

[2]. Michael Mc Guire : (The adverse effects of divorce and how they have changed the family structure). 2000,P:1-2..

[3]. Kathleen O: (Psychological and emotional aspects of divorce), 1997-2012,P:1

[4]. Wendy M.: (Hand book of separation and divorce). Ifirst edition. New York and Canada. 1996,P:3,82.

[5]. Stone, et al: (The Destruction of Cultural Heritage in Iraq). Rochester, NY: The boy dell Press,2008.2440.

[6]. Jason L: (Drastic effects of divorce on family members). Health guidance, 2012, P:1 
[7]. Julienne B. Derichs (The Impact of Divorce on Families), couples counseling today Newsletter, 2009, $\mathrm{P}: 1$

[8]. Advance report of final divorce statistics 1988: (Monthly Vital Statistic Report). 39(12 (supplemet2)). 1991-05-21.

[9]. Brinig , et(These boots are made for waking: Why Most Divorce Filters are women) American law and Economics Review,2000, Vol :2,pp: 126- 169.

[10]. Aseltine, et al: (Marital disruption and depression in a community sample). Journal of Health and Social behavior, 1993, 34;23-251

[11]. Jennifer Meclntosh, Susie burke, Nicoleat Dour and Heather Gridley : (Parenting after Separation A position Statement prepared for The Australian Psychological Society).july2009,pp;1-100.

[12]. Booth, A,,\&Amato, P.R: (Divorce and psychological stress). Journal of Health and Social Behavior, 1991,32,396-407.

[13]. Demo, D.H., \& Acock, A.C: (Motherhood,marriage : The effects of family structure and family releanships on mothers, well-being). Journal of family lessues, 1996,17, 338_407.

[14]. Immigration and Refugee Board of Canada, Iraq: (Procedure for divorce; wether a woman can divorce her husband if he is out of the country). Refworld, 29May2002, P:1.

[15]. Hetherington, E.M., Stanley-Hagan, M., \& Anderson, E.R. Marital transitions: A child's perspective. Amercan Psychologist, 1989, 44,303-312.

[16]. Baum, N. Divorce process variables and the co-parental relationship and role fulfillment of divorced parents.Family Process,2003,42,117-131.

[17]. Astone N, \& Mclanahan, S., : (The role of mother_only families in reproducing poverty). In Huston, Aletha C. (Ed). New York, 1994,pp,51-78.

[18]. Simons, R.L. \& Associates: (Understanding differences between divorced intact families: Stress,interaction and child outcome), 1996,P:1. 